\title{
Método e eSTRUTURA SOCIAL: A CRÍtica MARXISTA DE ISTVÁN MÉSZÁros À LóGICA DE Hegel
}

\author{
Rafael Lessa Vieira de Sá Menezes ${ }^{1}$
}

\begin{abstract}
Resumo: Neste trabalho discute-se a crítica de István Mészáros à Lógica de Hegel. Aponta-se como o marxismo realiza a crítica aos pontos de partida e de chegada da Ciência da lógica, quais sejam, o pensamento sem pressupostos e o círculo auto-constituído da Lógica. Com isso, indica-se a diferença entre os modos hegeliano e marxista de conceber o enraizamento do conhecimento no processo de vida real. Discute-se ainda como István Mészáros realizou uma dura crítica à hipostasiaçáo do método dialético em G. Lukács, crítica esta que se apóia na rejeição de um método que deixa de prestar contas ao ser e que, por isso, acaba lidando com a identidade entre conhecimento e ser como uma mera postulação abstrata.
\end{abstract}

Palavras-chave: Método. Ciência da lógica. Dialética. Estrutura social.

\section{ENRAizamento do CONHECIMENTO NO PROCESSO DE VIDA REAL: CRÍTICA AO PENSAMENTO SEM PRESSUPOSTOS E AO CÍRCULO AUTO-CONSTITUÍDO DA LÓGICA}

Hegel inicia sua Lógica com o puro $\operatorname{ser}^{2}$ ("o pensamento é"), do qual as categorias do pensamento passam a derivar. O ponto de partida de Hegel no puro ser não é aleatório, mas tem relação com a noçáo de um pensamento sem pressupostos (HOULGATE, 2006, p. 29 e ss.). A maneira hegeliana de conceber o pensamento sem pressupostos se afasta da tradição filosófica

\footnotetext{
${ }^{1}$ Doutor em Direito pela Universidade de São Paulo (USP), São Paulo, SP - Brasil. (D) https://orcid. org/0000-0002-2078-1030 E-mail: rafaeldesamenezes@gmail.com

Pós-doutor em Democracia e Direitos Humanos pelo Ius Gentium Conimbrigae / Centro de Direitos Humanos, Coimbra - Portugal.

${ }^{2}$ Hegel, 1816, $\$ 99:$ "Thus the beginning must be an absolute, or what is synonymous here, an abstract beginning; and so it may not suppose anything, must not be mediated by anything nor have a ground; [...] The beginning therefore is pure being."
}

http://dx.doi.org/10.1590/0101-3173.2019.v42n2.06.p107 
que parte do "eu" como constitutivo das coisas ("eu penso, logo existo") (HOULGATE, 2006, p. 32).

Partir do "eu" não permitiria um conhecimento objetivo das categorias do pensar, daí porque o ponto de partida é o puro ser. Ao mesmo tempo, trata-se de um modo de proceder próprio da tradição filosófica crítica, a qual aparece na "intenção crítica da dúvida metódica cartesiana" e na "luta de Bacon contra os 'ídolos', passando pela programática 'revolução copernicana' da 'filosofia crítica' de Kant” e, finalmente, na 'negação negativamente autorreferida’ de Hegel” (MÉSZÁROS, 2009, p. 59). Descartes já traçara o modo de proceder metódico, no sentido de que seria preciso suspender todas as certezas para se chegar ao verdadeiro conhecimento ${ }^{3}$. Em Hegel, seria, outrossim, preciso abstrair tudo e contemplar o que resta diante dos olhos, isto é, se despir de todas as certezas, contemplando o puro ser como ponto de partida, sem qualquer estrutura subjetiva ou lógica dada ou anterior a este puro ser.

Assim, a demanda crítica tradicional da filosofia, a saber, de suspender todas as certezas sobre o pensamento, toma uma forma particular em Hegel, que partirá do puro ser como o único elemento que resta quando se suspendem todas as certezas, quanto o pensamento afasta todas as pressuposiçóes. Para Hegel, a tarefa da filosofia seria, assim, "estabelecer quais categorias são imanentes ao entendimento concebido simplesmente como pensamento enquanto tal" (HOULGATE, 2006, p. 24). Por isso o ponto de partida de Hegel é o puro ser, a partir do qual as outras categorias surgem como autodesenvolvimento deste puro ser até o conceito absoluto, a idéia, que também é um modo de aparecer do próprio ser.

Hegel reivindicava o mérito de ter "rompido com todo modo representacional de pensar com o propósito de o estabelecer numa perspectiva do que ele chama de 'o Conceito', onde o pensamento se torna consciente de sua identidade consigo mesmo em todo e cada conteúdo que ele pensa" (LONGUENESSE, 2007, p. 13). O conceito, em Hegel, está no ponto de chegada da Ciência da lógica e, ao mesmo tempo, fundamenta todo o sistema. No próprio desenvolvimento das categorias do pensamento estas se mostram

${ }^{3}$ Com isto, Descartes considera "o que é necessário a uma proposição para ser verdadeira e correta; pois, já que encontrara uma que eu sabia ser exatamente assim, pensei que devia saber também em que consiste essa certeza. $\mathrm{E}$, ao perceber que nada há no eu penso, logo existo, que me dê a certeza de que digo a verdade, salvo que vejo muito claramente que, para pensar, é preciso existir, concluí que poderia tomar por regra geral que as coisas que concebemos muito clara e distintamente são todas verdadeiras, havendo somente alguma dificuldade em notar bem quais são as que concebemos distintamente." (DESCARTES, 2000, p. 20). 
como um círculo auto-constituído ao aparecerem como conceito. $\mathrm{Na}$ Lógica, o ceticismo da consciência diante da dicotomia conhecimento/ser é aclarado para mostrar como a realidade tem a mesma estrutura lógica que o pensamento (HOULGATE, 2006, p. 147).

Na medida mesma em que se coloca este "círculo auto-constituído", poder-se-ia colocar em dúvida se não haveria um pressuposto no pensamento sem pressupostos, se não haveria mesmo um pressuposto no ponto de partida da Ciência da lógica. Segundo Houlgate, "este fundamento - o círculo - não é, e não pode ser, pressuposto no começo do desenvolvimento" (HOULGATE, 2006, p. 50). Ao invés, o fundamento só emerge - e o círculo só se constitui - através da "auto-negação do ser imediato do começo". O próprio Hegel, na Ciência da lógica, é que afirma que o método não pode ser antecipado (HEGEL, 1816, \$ 1812).

A crítica de Feuerbach (HOULGATE, 2006, p. 55 e ss.) ${ }^{4}$ à Lógica de Hegel é a de que nesta se pressupóe aquilo que deveria ser provado: a existência do absoluto, da Idéia, a qual torna necessário cada estágio pelo qual as categorias passam ao partir do puro ser (HOULGATE, 2006, p. 55). Com isso, Hegel não começaria a "Ciência da lógica", como ele alega, com o puro ser, mas com a própria Idéia absoluta, pois esta já é uma certeza para o filósofo antes de ele escrever a Lógica: "A idéia finge emergir de um conceito indeterminado no qual ela está completamente ausente, mas de fato 'ela se coloca previamente como verdade'." (FEUERBACH, 1983, p. 112 apud HOULGATE, 2006, p. 55). Em se aceitando esta crítica de que Hegel não suspende todas as pressuposiçóes em sua Lógica, o pensamento sem pressupostos seria um mero artifício engenhoso para mostrar como o conhecimento está intimamente ligado ao ser (a ponto de serem nada mais que coincidentes). Isto tem o condão, na crítica marxista, de colocar a própria dúvida metódica sob suspeita, por se tratar de um proceder abstrato que não presta contas ao ser, apesar do momento genuinamente crítico da orientação negativa da "filosofia crítica"s. (MÉSZÁROS, 2009, p. 59-60).

\footnotetext{
${ }^{4}$ Aí, o autor se refere ao ponto de vista de Feuerbach como um dos pontos de vista ortodoxos na interpretação de Hegel.

${ }^{5}$ Concluindo o filósofo que "os limites negativos de todas as abordagens, não importa quão pronunciados, são também barreiras positivas (ou seja, margens para a ação objetivamente circunscritas) dentro das quais determinados avanços tornam-se possíveis" (MÉSZÁROS, 2009, p. 59-60), de modo que mesmo os direitos do homem, que aparecem como negatividade abstrata sob o capitalismo, seriam exigidos, em sua concepçáo socialista, como um "traço necessário do período de transição em sua totalidade" (MÉSZÁROS, 2009, p.60).
} 
Stephen Houlgate critica, porém, a interpretação de Feuerbach ${ }^{6}$, a qual é tida como parte da ortodoxia sobre Hegel, por pressupor "a princípio e sem dúvida" que Hegel pressupôe "a princípio e sem dúvida" a finalidade e o resultado de sua filosofia - ou seja, Feuerbach não "leva a sério a clara insistência de Hegel de que o começo da Lógica 'não pode pressupor nada'” e admite que Hegel começa a filosofar dentro de um "sistema dialético cuja completude ou fechamento ele pressupóe, explícita ou implicitamente, desde o começo" (HOULGATE, 2006, p. 56-57). Houlgate, assim, entende que a Lógica não começa com a idéia pressuposta do absoluto, mas com a suspensão radical de todas as pressuposiçôes sobre o pensamento e sobre o ser, de modo que não há nenhuma finalidade pressuposta no pensamento sobre o puro ser indeterminado, nem há um método de progressão lógica pressuposto (HOULGATE, 2006, p. 57), o que, ademais, é enfatizado pelo próprio $\mathrm{Hegel}^{7}$. Ademais, defende que se Hegel assegura desde o início da obra qual o resultado da Lógi$c a^{8}$, ele o faz para provocar o leitor a constatar o ponto de chegada, náo para colocar este resultado como o começo 9 (HOULGATE, 2006, p. 50). Mesmo porque o projeto de Hegel na Lógica é derivar as categorias básicas do pensamento do próprio pensamento, mas apenas ao final da Ciência da lógica Hegel descobre que o pensamento do ser é na verdade o pensamento da natureza; antes disso, todas as categorias básicas do pensamento foram derivadas e determinadas a partir do puro ser (HOULGATE, 2006, p. 53).

É o próprio Hegel, aliás, que afirma que o método não pode ser antecipado (HEGEL, 1816, $\$ 1812$ ). Entretanto, a afirmação, a insistência e a ênfase de Hegel de que não há um método de progressão lógica pressuposto não é suficiente para que se convença sobre a possibilidade de se partir de um pensamento sem pressupostos ${ }^{10}$. Resta, ademais, náo explicado porque a filo-

${ }^{6}$ Critica também outras interpretaçóes neste sentido. Apenas para citar, Houlgate se refere a Feuerbach, a Schelling e a McTaggart como formadores da ortodoxia sobre Hegel, mas também a Hartmman, Heidegger, Derrida e Levinas, citando mais adiante Marx, Gadamer, Nietszche e Deleuze, todos empenhados em demonstrar que há algo "pressuposto" (que há uma "condição de possibilidade") no sistema de Hegel.

7 O trecho da afirmação está em HEGEL, 1816, $\$ 34$.

8 Vide HEGEL, 1816, $\$ \$ 102$ e 104, onde a insistência de Houlgate num pensamento sem pressupostos parece contrastar com o que o próprio Hegel afirma. Como se coloca no texto, Houlgate rebate este ponto.

${ }^{9}$ É o que se conclui da própria leitura de Hegel, 6, $\$ 1805$.

${ }^{10} \mathrm{Na}$ própria visão de Hegel no prefácio da Fenomenologia do espirito, a verdade é o processo, o círculo que pressupóe seu fim como uma finalidade, tendo seu fim também como um começo. Para (HOULGATE, 2006, p. 59), esta passagem também se aplica à Lógica, mas não confirma a leitura 
sofia começa numa afirmação pontual, sem pressupostos, e se desenvolve num círculo que passa a fundamentar também aquele ponto inicial.

Ainda, Hegel, ao abstrair tudo, não pressupõe um método dialético, sequer pressupóe que a lógica formal seja aceitável ou não; o método dialético e a lógica formal poderiam eventualmente decorrer da análise crítica das categorias do entendimento, mas não serem pressupostos diante de tais categorias. Assim, "a dialética pode muito bem, portanto, se revelar como o método apropriado para o pensamento filosófico” (HOULGATE, 2006, p. 34), mas isto não é uma pressuposição legítima no modo de proceder da crítica filosófica hegeliana, podendo, no máximo, ser uma constatação posterior. Neste sentido, "se o pensamento e o discurso do erudito hegeliano ou do sábio são dialéticos, é apenas porque refletem fielmente o movimento dialético do real do qual fazem parte, e do qual fazem a experiência adequada ao se entregar a ele sem nenhum método preconcebido" (KOJÈVE, 10, p. 429).

Assim, Hegel constata a dialética própria do modo como se comportam as categorias fundamentais do pensamento quando se parte de um pensamento sem pressupostos, quando se parte do puro ser e se o desenvolve nas demais categorias do pensamento até o conceito, e com isso expóe o próprio movimento dialético do real. É no comportamento de tais categorias que se vislumbra a dialética. Embora este comportamento reflita algo que ocorre também no real, no movimento dialético do próprio real, o modo como Hegel, embora indo além, aceita, com Kant, que as categorias têm sua fonte no pensamento ${ }^{11}$, pode ser um dos pontos no qual Hegel decisivamente se mantém nos limites do idealismo e não passa ao materialismo.

A crítica marxista se apóia, incialmente, naquela interpretação de Feuerbach sobre Hegel. Apontar o caráter "místico” da filosofia de Hegel é indicar como a Ideia, o Conceito ou o Absoluto permeiam todo o sistema hegeliano, estando presente mesmo no alegado começo sem pressupostos. Embora a Lógica pareça se desenvolver a partir do puro ser e constituir um

ortodoxa de Hegel, pois ela não descreve o que ocorre no começo da filosofia, sendo certo que a filosofia não começa como um círculo, ela se desenvolve e se torna um círculo. No começo da filosofia, há apenas a "pura imediatidade" - na Fenomenologia, a imediatidade da certeza-sensível, e na Lógica, a imediatidade do puro ser.

${ }^{11}$ Houlgate (2006, p. 27), onde se observa que Hegel considera sua Lógica um refinamento da filosofia kantiana, e um dos modos deste refinamento se dá quando a Lógica "completa a derivação genética das categorias que (de acordo com Fichte) são tidas como necessárias no entendimento de Kant de que as categorias têm sua fonte apenas no pensamento”. 
aparecimento necessário do Conceito como seu fundamento, este já estaria presente desde o começo.

O ponto de partida de Marx é também uma crítica ao próprio Feuerbach, tanto que Marx coloca inicialmente sua crítica como uma forma de naturalismo ${ }^{12}$, se contrapondo tanto ao "idealismo" hegeliano como ao "materialismo" feuerbachiano. Feuerbach jamais teria deixado o reino do pensamento ou da "fraseologia", ao contrário de Marx, que já nos Manuscritos de Paris partia "de um fato nacional-econômico, presente" ${ }^{13}$, não de um fato imaginado, de uma postulação idealista ${ }^{14}$. Marx aponta que a filosofia e a reflexão crítica de Feuerbach (a exposição da religião como alienação) se desenvolviam de modo "abstrato e não-histórico" (AMERIKS, 2000, p. 270), percebendo apenas indivíduos isolados na sociedade civil (MARX, 2007, p. 539). A crítica de Marx, assim vai no sentido de que "qualquer posição filosófica pode ser criticada... como 'mero criticismo' ou 'ideologia', isto é, como mero reflexo de forças mais básicas” e de que as premissas das quais se deve partir são, não dogmas ou abstrações, mas premissas reais (AMERIKS, 2000, p. 270).

A crítica marxista a Hegel está apoiada também na problematização do modo de proceder da tradição "crítica" da filosofia ocidental: a impossibilidade de abstrair tudo e a desnecessidade de fazê-lo para se chegar a um conhecimento seguro e verdadeiro ${ }^{15}$. Este é um ponto central para a compreensão

\footnotetext{
${ }^{12}$ Ameriks (2000, p. 264), que ainda observa: “'Materialism' at this point is Marx's term not for an ontological position but for what he takes to be Feuerbach's inadequately critical version of epistemology."

${ }^{13} \mathrm{Ou}$ seja, daquela observação de que "o trabalhador se torna tanto mais pobre quanto mais riqueza produz, quanto mais a sua produção aumenta em poder e extensão" (MARX, 13, p. 80).

${ }^{14}$ Não se acata aqui a visão de Ameriks (2000), para quem “Marx’s own earlier work, even his notes on alienated labor, were themselves still an instance of Feuerbachian philosophy. It is true that he begins 'from a contemporary economic fact. The worker becomes poorer the more wealth he produces.' Marx does not stay at the economic level, however, but moves from this fact to explain how it displays the structure of human alienation as such." Isto porque o materialismo de Marx não trata de se manter sempre numa ciência positiva a partir de uma constataçáo de um fato econômico como fundamento da vida social e do próprio pensamento por esta engendrado. Tal materialismo diz respeito a um fato real, material, do qual parte, ainda que se mantenha ao nível eminentemente filosófico para discutir, por exemplo, o conceito de alienação.
}

${ }^{15}$ Segundo Houlgate (2006, p. 40, grifo nosso), "if readers of Hegel's Logic are to be thoroughly self-critical, they have no alternative but to set aside all their presuppositions about thought, its categories, and rules". Entretanto, tal posição é criticável: Marx não tem pressupostos filosóficos, mas colhe a própria liçấo de Hegel para determinar a verdadeira origem de todo método: a origem social do método, como se verá no decorrer deste trabalho, a verdadeira "realização da filosofia", ou ao menos o caminho para esta realização, a atualização do projeto filosófico da modernidade de descobrir o modo para chegar a um conhecimento seguro. A realização de Marx coloca em movimento a história, não a 
de uma filosofia marxista, qual seja, o de que não é possível abstrair de tudo, pois quando se "abstrai de tudo" o começo da reflexão será ainda algo preso a um último impulso humano determinado pelo próprio contexto do sujeito cognoscente.

Algo desta noção é herança da filosofia hegeliana, mas apenas a crítica a esta filosofia enquanto sistema leva a uma filosofia marxista ${ }^{16}$. Nesta, a crítica está centrada no distanciamento entre a filosofia e o mundo real (MÉSZÁROS, 1987, p. 160). Para Marx, a filosofia deveria ser "compreendida em relação com o desenvolvimento objetivo das forças e das relaçóes de produção, como parte integrante da totalidade da práxis social” (MÉSZÁROS, 1987, p. 161), e o pensamento, e até mesmo as "fantasmagorias", corresponderia a sublimações resultantes do processo vital, "do processo da vida material que pode ser observado empiricamente e que repousa em bases materiais” (MÉSZÁROS, 1987, p. 161).

Assim, o modo de proceder da tradição crítica da filosofia ocidental está na raiz do problema acerca da maneira de conceber a relação entre conhecimento e ser. A elaboração de um pensamento sem pressupostos, que abstrai de tudo para partir de uma certeza segura, leva a uma atenção de tal forma fixada no método que a atenção a ser dispensada ao emparelhamento entre ser e pensamento fica esmaecida, de modo que o ser aparece já como expressão idealizada e se desenvolve por meio de regras do pensar. A lógica, assim, aparece apenas como um aspecto abstrato do mundo real já racional, o qual conforma o conteúdo objetivo desta lógica. Ao concentrar-se apenas no método, numa dúvida metódica, parece ser possível abstrair de tudo, mas este modo de proceder leva a uma ontologia que se autonomiza do ser humano em seu contexto histórico e social. Em Hegel, a identificação ou a não distinção entre ser e conhecimento pode ser visto como o ápice deste modo de proceder sem pressupostos. Bastaria examinar a estrutura do pensamento para se descobrir a estrutura do ser.

paralisa, já que se trata de descobrir que o modo para se chegar a um conhecimento seguro é examinar o objeto em seu desenvolvimento, examinar a própria realidade social existente enquanto fundamento do conhecimento, da filosofia e do método. Assim, a ideia de que o pensamento de Hegel só seria passível de uma crítica imanente deve ser criticada com a crítica ao ponto de partida hegeliano da abstração de tudo, de um pensamento sem pressupostos.

${ }^{16}$ Rejeita-se, neste ponto, expressamente, como se vê, a noção de que Marx tenha negado a filosofia, tratando-se, mais propriamente, de uma busca pela superação desta, afinal apenas possível num futuro histórico contingente. 
Para Marx não importa tanto a questão em si do ponto de partida da filosofia - o ponto de partida desta deve ser a vida real dos seres humanos contextualizados, concebido o pensamento como emanação direta do comportamento material destes. A dúvida metódica é posta de lado como um artificioso ponto de partida no abstrato. Marx, realmente, não levou a sério a afirmação de Hegel de que partia de um pensamento sem pressupostos, ou, ao menos, não se convenceu de que Hegel tenha chegado a realizar seu intento de partir de uma dúvida metódica e começar a Lógica despindo-se de todos os pressupostos, com o puro ser.

Neste sentido, o sistema concebido por Marx radicaliza algo que era já problematizado por Hegel ao apontar a identidade entre ser e pensamento: que o conhecimento possui uma base contextual e social inarredável, de modo que náo se pode suspender toda certeza. Aí estaria uma herança da filosofia hegeliana na filosofia marxista, mas uma herança radicalizada, pois envolve uma crítica às mistificações hegelianas de buscar um pensamento sem pressupostos e de chegar a um conceito e a um círculo auto-constituído. Na tradiçáo marxista, a crítica a este modo de proceder abstrato aponta como ele acaba por minar a constatada identidade entre ser e pensamento. As certezas e mesmo os pontos de partida só podem aparecer no próprio contexto social em que o filósofo está.

Poder-se-ia questionar se a filosofia marxista não seria simplesmente uma repetição da lógica objetiva de Hegel, se não seria uma confirmação da concepção deste segundo a qual o conhecimento tem suas raízes num processo vital natural e histórico (LONGUENESSE, 2007, p. 161). B. Longuenesse vê esta concepção de Hegel como uma posição crítica em relação à tradição da metafísica que entendia que a objetividade apenas existia através da constituição da subjetividade (LONGUENESSE, 2007, p. 161) 17. A “ontologia” de Hegel seria uma ontologia num sentido muito peculiar, pois "a Ciência da lógica não é uma doutrina do ser qua ser, ela é uma doutrina do ser como ser pensado", sendo que a Lógica propóe não apenas uma ontologia, mas ontologias, determinadas "a cada tempo por diferentes 'atitudes do pensamento com relação à objetividade” (LONGUENESSE, 2007, p. 161). Neste sentido, é de grande relevância a questão sobre se a "doutrina do conceito" não representaria "um retorno a uma metafísica não-crítica”, a um "racionalismo

\footnotetext{
${ }^{17}$ Hegel afirma ao mesmo tempo que "o mundo é o que é apenas em virtude de uma atividade e que esta atividade é o fundamento da necessidade absoluta da estrutura do mundo", concluindo a autora que se trata do mais forte aspecto original da "ontologia" de Hegel.
} 
triunfante”. (LONGUENESSE, 2007, p. 162). Longuenesse entende que tal leitura só seria possível com uma leitura isolada da doutrina do conceito, uma leitura que não considerasse a lógica objetiva. Mas problematiza também se o próprio Hegel teria incorrido em tal leitura, deixando a questão em aberto e observando que não se trata de "salvar" Hegel a qualquer custo da acusação de um racionalismo dogmático (LONGUENESSE, 2007, p. 162) ${ }^{18}$.

A crítica de Hegel à metafísica e a colocação da lógica objetiva como começo da Lógica (HEGEL, 1816, \$ 85) são da maior importância. Mas a tradição marxista em geral interpretou, como apontado acima, o sistema de Hegel como completamente permeado pelo conceito absoluto, já presente no ponto de partida da Lógica. Assim, segundo este modo de interpretar Hegel, a lógica subjetiva ofusca a lógica objetiva ${ }^{19}$. A própria noção de que o pensamento teria raízes num processo vital natural e histórico apenas se sustenta no final da Lógica na medida em que conhecimento e realidade, conceito e ser, são identificados.

A leitura de Hegel feita por István Mészáros dá atenção especial à interrelação entre a Lógica e a filosofia moral hegeliana. Nela, seguindo a crítica feuerbachiana e marxista, aponta-se como o conceito pauta toda a Lógica, apesar do anunciado proceder sem pressupostos. Efetivamente, o proceder sem pressupostos apenas redundaria, nas filosofias do direito e da história, numa atitude "apologética" e num "positivismo acrítico" diante do desenvolvimento real do sistema do capital (MÉSZÁROS, 2009, p. 66). O “círculo dos círculos" hegeliano ofusca a lógica objetiva e seu anunciado proceder crítico.

István Mészáros radicaliza a concepção de que o conhecimento tem raízes num processo vital natural e histórico e interpreta o sistema de Hegel

\footnotetext{
${ }^{18}$ A autora conclui que "conversely, one may wonder if a rereading of Hegel's system in light of the whole movement of the Logic rather than merely the structure provided by the concept, wouldn't produce critical effects on the scale of the radicalization of the transcendental enterprise expounded in the Logic. Answering this question would require a study of far greater magnitude than that proposed in this essay. It is not impossible that it would bring into new light the position occupied by Hegel in modern philosophy." De acordo com a crítica marxista, entretanto, aquela releitura não seria possível em razáo do modo como o conceito permeia toda a Lógica.

${ }^{19}$ Fausto (1993, p. 170-171), entende como injustas as "críticas ao idealismo hegeliano como um idealismo em que o objeto é absorvido pelo sujeito, mesmo se limitadas ao momento da idéia absoluta", já que Hegel não abandona a idéia de adequação. Mas aponta que "dada a redução do objeto, em Hegel, a adequação se faz, finalmente entre um argumento ontológico subjetivo e um argumento ontológico também subjetivo. Se em Marx, como em Hegel, há prova ontológica e adequação, no primeiro é a adequação que regula a prova ontológica... enquanto que no segundo é pelo contrário a prova ontológica que regula a adequação".
} 
como um sistema aderente à ordem dominante que estão se consolidava, no qual a Lógica acaba cumprindo o papel de uma mera estrutura conceitual para a justificação da visão idealizada da história (MÉSZÁROS, 2011, p. 190) e do direito. Por isso a Lógica de Hegel não pode ser "salva" por uma leitura menos severa da doutrina do conceito e do "círculo dos círculos". Desde o começo, a Lógica estaria permeada pela Ideia, teria isto em vista.

Segundo István Mészáros, na medida em que "a negatividade da pseudomediação especulativa 'inclina-se de volta a sua origem'”, Hegel oferece um "sistema que idealisticamente 'supera' as contradições do mundo real na fictícia 'esfera da liberdade' da Noção [do Conceito], enquanto deixa tudo na realidade como antes” (MÉSZÁROS, 2009, p. 59). Isto é, a estrutura da Lógica, que se fecha num círculo que se auto-constitui, não prestaria contas às contradiçóes do mundo real, apoiando-se numa suposta liberdade do Conceito que, no limite, não permite ao "ser real" mostrar-se em seu desenvolvimento próprio na reflexão. Este não seria mais que "um sistema que legitima a ordem estabelecida ao pregar que 'o que é racional é real e o que é real é racional'” (MÉSZÁROS, 2009, p. 59).

Ao afirmar que, na filosofia do direito, a "positividade extraída da 'negação da negação', com seu princípio abertamente defendido da 'reconciliação com o presente" representaria a "única síntese válida da substantividade 'compreendida”, István Mészáros imputa à Lógica um papel de estrutura metódica preconcebida. Justamente as noçóes de um pensamento sem pressupostos e de um ponto de partida sem um método preconcebido acabam sendo deixadas de lado por Hegel quando parte para o exame do "ser-aí", quando se coloca no terreno das ciências positivas. Na leitura de István Mészáros, assim, a filosofia moral explicita o distanciamento de Hegel da noção de que o conhecimento está enraizado na realidade natural e histórica e na estrutura social.

A crítica marxista a um começo metódico, sem pressupostos, não afasta de todo a pretensão hegeliana de excluir a antecipação de um método. Este realmente decorre do próprio modo como as categorias são concebidas, não podendo ser rigidamente antecipado, mas aquele modo de conceber as categorias também decorre do próprio contexto da vida natural e histórica do ser humano. Entretanto, o modo como Hegel passa da lógica objetiva à subjetiva, como se se tratasse de um mero desenvolvimento de categorias, revela o nível de abstração em que opera a Ciência da lógica, desvinculando-se de discussóes contextuais e, no limite, buscando realizar a pretensão de esclarecer o modo como o conhecimento se desenvolve, mas o fazendo apenas especulativa e 
abstratamente - no limite, assim, abandonando a primeira concepção de que o pensamento está enraizado no processo de vida real, natural e histórico. Este modo de conceber o próprio conhecimento será retomado e levado mais a sério pelo marxismo, a ponto de o abandono mencionado ser explicado por István Mészáros justamente pelo enraizamento do pensamento de Hegel no seu próprio processo de vida natural e histórico.

Neste sentido é que István Mészáros remete o "círculo dos círculos" hegeliano, o círculo que se auto-constitui, a uma postura apologética diante do sistema do capital que, substantivamente, se impunha contra todo o impulso de liberdade, mas que, para Hegel, não era mais do que o próprio desenvolvimento rumo à liberdade. Por isso, "as mesmas determinaçôes e contradiçôes do horizonte construtivo do capital são reproduzidas” na filosofia de Hegel "ao nível mais elevado de abstração". Assim fundamenta o filósofo húngaro:

De fato, as contradiçóes idênticas e a circularidade concomitante são reproduzidas talvez de modo mais conspícuo que em qualquer outro lugar precisamente no âmbito sublimado e transubstanciado da lógica hegeliana. Assim, como resultado das geniais transformaçóes filosóficas de Hegel, a circularidade socialmente inevitável do ponto de vista da economia política é elevada ao nível do mais sublime princípio metodológico da "ciência" e conscientemente adotada como o ponto pivotal de todo o sistema. (MÉSZÁROS, 2009, p. 54).

Em razão de contradições internas e de limitaçôes estruturais do ponto de vista da economia política, Hegel afasta-se da noção de enraizamento do conhecimento no processo de vida real nos seguintes termos:

A Ideia absoluta é o único objeto e conteúdo da filosofia. Pois contém toda a determinação, e sua essência é o retorno a si mesma através da autodeterminação ou particularização, ela possui várias fases [...] a mediação obtém seu curso através da determinação; chegando a um conteúdo por meio de um Outro aparente de volta a seu início de tal maneira que não apenas reconstitui o começo (enquanto determinado, contudo), mas que o resultado é igualmente determinação transcendida, e portanto é reconstituição da indeterminação primeva com a qual o método originou-se. [...] Por motivo da natureza do método que fora demonstrado a ciência aparenta ser um círculo que retorna a si mesmo, pois a mediaçáo inclina-se de volta a sua origem ou simplesmente substrato. Ademais, este círculo é um círculo de círculos; pois cada membro, sendo inspirado pelo método, é intro-Reflexão, a qual, retornando ao começo, é ao mesmo tempo a origem de um novo membro. [...] Assim, a Lógica também, 
na Ideia absoluta retornou a esta simples unidade que é o seu começo. (HEGEL, 1816, \$\$1814 apud MÉSZÁROS, 2011, p. 54).

A crítica filosófica ocidental, apoiada na negatividade crítica, que chega à "negação da negação" de Hegel, não pode ir muito longe, pois suas fronteiras "simultaneamente também representam os limites intransponíveis do horizonte social compartilhado" pelos pensadores da "dúvida metódica", da luta contra os "ídolos", da "filosofia crítica" e da "negação negativamente autorreferida” (MÉSZÁROS, 2009, p. 59). Assim, o modo de enfrentar o problema do emparelhamento entre ser e conhecimento, entre realidade e pensamento, partindo de uma problematização dos "limites definitivos da razão humana em si mesma” seria uma representação errônea acerca dos limites da inteligibilidade filosófica, limites estes que "são, de fato, as premissas práticas da 'sociedade civil' capitalista aceitas de modo acrítico, concebidas como as depositárias de intercâmbios individuais agregativos.” (MÉSZÁROS, 2009, p. 62) ${ }^{20}$.

O que falta à tradição crítica é justamente uma "análise adequada das determinaçôes estruturais da ordem estabelecida", as "determinaçóes objetivas da lei do valor” (MÉSZÁROS, 2009, p. 63), sendo que nesta lacuna não se envolvem meros desvios conceituais decorrentes do modo de conceber a ordem social estabelecida, mas uma "consequência necessária das determinaçôes ideológicas subjacentes” (MÉSZÁROS, 2009, p. 63) ${ }^{21}$. Em Hegel, falta o exame lógico de categorias pensadas desde o ser, contra o exame da lógica do conhecimento que apenas por premissa seria enraizado no ser.

\section{ConclusóES}

Este trabalho buscou examinar alguns aspectos da Lógica de Hegel, em especial no que se refere à crítica a ela empreendida por István Mészáros.

\footnotetext{
${ }^{20}$ Onde István Mészáros arremata que “é inevitável que tal modelo de uma 'sociedade civil' intrinsecamente - e inalteravelmente - individualista transforme as determinaçôes objetivas de problemas sociais em problemas elusivos de modo fatal".

${ }^{21}$ Nos expressivos termos de István Mészáros: "O que precisa ser enfatizado aqui é que a 'ilusão do iluminismo' referente aos intercâmbios sociais determinados pela razáo e pelo contato idealizado da ordem social estabelecida, como manifesto nas explicaçóes mais implausíveis de séculos de pensamento burguês - do 'consenso tácito de Locke à concepçâo kantiana do contrato social como 'ideia regulativa da razão', e da 'vontade geral' de Rousseau à caracterização hegeliana da medida enquanto 'convenção': todas completamente desprovidas de partes contratuais reconhecidamente ao acordo filosoficamente hipostasiado - não é a causa de tais desvios conceituais, mas, ao contrário, a consequência necessária das determinaçóes ideológicas subjacentes."
} 
Por isso, apontou-se uma possível crítica a dois extremos problemáticos, aos pontos de partida e de chegada da Ciência da lógica: o puro ser que aparece em decorrência de um pensamento sem pressupostos e o conceito absoluto como formador de um círculo lógico que se auto-constitui. A crítica da tradição marxista vai no sentido de que no primeiro extremo já estaria pressuposta a unidade ser e conhecimento (questão já exposta para a consciência na Fenomenologia do espirito), e no secundo extremo apenas apareceria esta pressuposição como auto-justificação.

A concentração no método e na Lógica, que se desenvolve sem prestar contas ao real, leva a uma ontologia que se autonomiza do ser humano em seu contexto histórico e social. Nos limites do idealismo, bastaria examinar a estrutura do conhecimento ou do pensamento para se descobrir a estrutura do ser. Não se passa, assim, ao materialismo nem na Lógica nem nas filosofias da história e do direito, sendo que nestas Hegel se vale de uma lógica pré-concebida e que acaba cumprindo uma função apologética do sistema do capital. A crítica marxista se resolve na noção de que o ser e o próprio método só podem ser determinados e fundados por aquele (pelo ser), tal qual ele aparece ao entendimento que leva em conta a totalidade da estrutura social - se trata de uma radicalização do próprio pensamento de Hegel, porém, com um combate a aspectos abstratos e idealistas que aparecem, por exemplo, nos mencionados extremos da Lógica. Com isso, pensa-se que fica assentada a diferença entre os modos hegeliano e marxista de conceber o enraizamento do conhecimento no processo de vida real.

A crítica marxista à dialética de Hegel se apoia numa crítica ao modo de proceder idealista deste, apontando que o desenvolvimento das categorias da Lógica, além de não partirem realmente de um pensamento sem pressupostos, não se interessa em prestar contas à realidade, apesar do anunciado emparelhamento entre ser e conhecimento. Neste sentido, a tradição marxista aponta a ontologia (Lógica) de Hegel como uma ontologia especulativa, que não cumpre o papel de explicitar o ser que estava implícito no puro ser indeterminado. A devida compreensão de Hegel e da sua crítica ao idealismo subjetivo é de grande valia para um sistema de pensamento que vê a natureza humana como necessariamente contextualizada, histórica. A crítica marxista a Hegel, que reaparece na crítica de István Mészáros a Hegel, por seu turno, pode ser de grande valia para releituras de Hegel que buscam reabilitar a lógica objetiva e o entendimento da própria lógica subjetiva como uma ontologia que envolve categorias descritivas do próprio ser em seu desenvolvimento pen- 
sado e não descritivas de um conhecimento que se apoia numa dada premissa, especificamente a de que tal conhecimento corresponde ao ser.

SÁ MENEZES, R. L. V. Method and social structure: István Mészáros' Marxist critique of Hegel's Logic. Trans/form/ação, Marília, v. 42, n. 2, p. 107-122, Abr./Jun., 2019.

ABstract: This paper discusses István Mészáros critique of Hegel's Logic. We point out how Marxism criticizes the presuppositionless thinkingand self-constituted circle of reasoning of the Science of logic. We thereby show the difference between the Hegelian and Marxist ways of conceiving the rooting of knowledge in the process of real life. We also discuss how Mészáros made a scathing critique of the hypostatization of dialectical method in Lukács work. This critique is based on the rejection of a method that fails to be accountable to the real world and therefore ends up treating the identity of knowledge and being as a mere abstract postulation.

KEY-wORDS: Method. Science of logic. Dialectics. Social structure.

\section{REFERÊNCIAS}

AMERIKS, K. The legacy of idealism in the philosophy of Feuerbach, Marx, and Kierkegaard. In: AMERIKS, K. (ed.). The Cambridge Companion to German Idealism. Cambridge: Cambridge, 2000. p. 358-385.

CARVER, T. Marx and Hegel's logic. Political Studies, v. XXIV, n. 1, p. 57-68, 1976.

DESCARTES, R. Discurso do método. Tradução de Enrico Corvisieri. São Paulo: Nova Cultural, 2000.

FAUSTO, R. Dialética marxista, dialética hegeliana: o capital e a lógica de Hegel. Discurso, n. 20, p. 41-77, 1993.

. Marx: lógica e política: investigações para uma reconstituição do sentido da dialética. Tomo I. 2. ed. São Paulo: Brasiliense, 1987.

. Marx: lógica e política: investigaçóes para uma reconstituição do sentido da dialética. Tomo II. São Paulo: Brasiliense, 1987.

HEGEL, G. W. F. Science of logic. Disponível em: http://www.marxists.org/ reference/ archive/hegel/works/hl/hlconten.htm. Acesso em: 15 maio 2018.

. Encyclopaedia of the philosophical sciences. Disponível em: http://www.marxists.

org/reference/archive/hegel/works/sl/sl_divis.htm. Acesso em: 18 jun. 2018. 
HOULGATE, S. The opening of Hegel's logic: from pure being to infinite. West Lafayette: Purdue University Press, 2006.

HUDIS, P. Conceptualizing an emancipatory alternative: István Mészáros’s Beyond capital. Socialism and Democracy, v. 11, n.1, p. 37-53, 1997.

KOJÈVE, A. Introdução à leitura de Hegel. Rio de Janeiro: Contraponto; UERJ, 2002.

LONGUENESSE, B. Hegel's critique of metaphysics. Tradução de Nicole J. Simek. Cambridge: Cambridge, 2007.

LUKÁCS, G. Prolegômenos para uma ontologia do ser social. São Paulo: Boitempo, 2010.

MARX, K. Manuscritos econômico-filosóficos. Tradução Jesus Ranieri. São Paulo:

Boitempo, 2004.

. Teses sobre Feuerbach. Tese IX. In: MARX, K.; ENGELS, F. A ideologia alemá. São Paulo: Boitempo, 2007.

MARX, K.; ENGELS, F. A ideologia alemã. São Paulo: Boitempo, 2007.

MÉSZÁROS, I. Estrutura social e formas de consciência: a determinação social do método. Tradução de Luciana Pudenzi, Francisco Raul Cornejo e Paulo Cezar Castanheira. São Paulo: Boitempo, 2009.

. Estrutura social e formas de consciência II: a dialética da estrutura e da história. Tradução de Rogério Bettoni. São Paulo: Boitempo, 2011.

. Marx filosófico. In: HOBSBAWN, E. J. História do marxismo: o marxismo no tempo de Marx. 3. ed. Tradução de Carlos Nelson Coutinho e Nemésio Salles. Rio de Janeiro: Paz e Terra, 1987. V. 1

- Para além do capital: rumo a uma teoria da transição. Tradução de Paulo César Castanheira e Sérgio Lessa. São Paulo: Boitempo, 2002. 2006.

. A teoria da alienação em Marx. Tradução de Isa Tavares. São Paulo: Boitempo,

PIPPIN, R. Hegel's practical philosophy: the realization of freedom. In: AMERIKS, K. (ed.). The Cambridge Companion to German Idealism. Cambridge: Cambridge, 2000.

Recebido: 30/09/2016

Aceito: 26/04/2019 
SÁ MENEZES, R. L. V. 